\title{
Nanoduct Sweat Conductivity Measurements in 2664 Patients: Relationship to Age, Arterial Blood Gas, Serum Electrolyte Profiles and Clinical Diagnosis
}

\author{
Rabia Gonul Sezer ${ }^{\mathrm{a}}$, Gokhan Aydemir ${ }^{\mathrm{b}}$, Abdullah Baris Akcan ${ }^{\mathrm{b}, \mathrm{d}}$, Cem Paketci $^{\mathrm{a}}$, \\ Abdulbaki Karaogluc, Secil Aydinoz ${ }^{\mathrm{b}}$, Abdulkadir Bozaykut ${ }^{\mathrm{a}}$
}

\begin{abstract}
Background: The Nanoduct ${ }^{\circledR}$ device has acceptable diagnostic accuracy, but there is not enough systematic data supporting its usage in the diagnosis of cystic fibrosis (CF).

Methods: A retrospective review of patients with an indication for the sweat test was conducted. The conductivity test was repeated in patients who had values higher than $60 \mathrm{mmol} / \mathrm{L}$, and they were referred for sweat chloride measurements. Associations between sweat conductivity measurements and age, gender, $\left(\mathrm{pH}, \mathrm{HCO}_{3}\right.$, $\mathrm{pCO}_{2}, \mathrm{Na}, \mathrm{K}, \mathrm{Cl}$ ), family history, consanguinity, indications for the test and number of hospitalization were studied.
\end{abstract}

Results: Among 2,664 patients, 16 children had sweat conductivity values higher than 80 . The median age of patients diagnosed with $\mathrm{CF}$ was 4 months old. Age, $\mathrm{pH}, \mathrm{HCO}_{3}, \mathrm{Na}, \mathrm{Cl}, \mathrm{K}$ and the sweat conductivity test were statistically related $(\mathrm{P}<0.001)$. The ROC curve showed very high agreement between the 2 nd conductivity test and the sweat test.

Conclusions: Patients suspected to have CF can be screened using

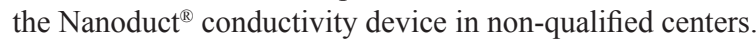

Keywords: Cystic fibrosis; Blood gases; Electrolytes; Serum

\section{Introduction}

The sweat test is the key method of investigation for the

\footnotetext{
Manuscript accepted for publication November 16, 2012

${ }^{\mathrm{a} D e p a r t m e n t ~ o f ~ P e d i a t r i c s, ~ Z e y n e p ~ K a m i l ~ M a t e r n i t y ~ a n d ~ C h i l d r e n s ~}$ Diseases Training and Research State Hospital, Istanbul, Turkey

${ }^{b}$ Department of Pediatrics, GATA, Haydarpasa Teaching Hospital, Istanbul, Turkey

${ }^{\mathrm{c}}$ Department of Pediatrics, GATA, Ankara, Turkey

${ }^{\mathrm{d} C}$ Corresponding author: Abdullah Baris Akcan, GATA Haydarpasa Egitim Hastanesi, Tibbiye Cd, Uskudar, 34668, Istanbul, Turkey. Email: barisakc@hotmail.com
}

doi: http://dx.doi.org/10.4021/jocmr1191w diagnosis of cystic fibrosis (CF) [1]. Conductivity is easier to perform than the classical Gibson and Cook method and requires a smaller amount of sweat [1]. The CF Foundation has approved the use of the Wescor Macroduct Sweat-Check conductivity analyzer for screening purposes at community hospitals [2]. Several studies have shown that conductivity haves an equal potential to discriminate between $\mathrm{CF}$ and non-CF patients [3-6]. Conflicting results about the correct diagnostic success rate of the Nanoduct ${ }^{\circledR}$ method have been reported $[5,7]$. Although the Nanoduct ${ }^{\mathbb{B}}$ device has acceptable levels of diagnostic accuracy, there is still not enough systematic data to support its usage in the diagnosis of CF [8, 9]. Sweat conductivity has been shown to be approximately $15 \mathrm{mmol} / \mathrm{L}$ higher than the sweat chloride concentration [4].

The main indications for the sweat test include a phenotype suggestive of $\mathrm{CF}$, family history of $\mathrm{CF}$, follow-up of newborn screening tests and the suspicion of an atypical CF phenotype [1]. The precise prevalence of CF in Turkey is unknown. However, in CF, the high heterogeneity and significantly higher number of mutations compared to other European countries has been demonstrated in several studies $[10,11]$. There is no newborn screening program for $\mathrm{CF}$ in Turkey at the present time; thus, the diagnosis is made when clinical symptoms exist and the patients' history is suspicious. This leads to the late diagnosis of $\mathrm{CF}$, with a mean age of $31.2 \pm 41.4$ (range: 1.5 - 168) months [12]. The early diagnosis of $\mathrm{CF}$ is important because the disease becomes chronic in children with a current median predicted age of survival of 37.4 years [13].

In this report, we document our experience comparing sweat conductivity results with metabolic alkalosis and hypoelectrolytemia in patients with a diagnosis of possible $\mathrm{CF}$ from 2006 - 2010. The aim of this retrospective study was to report our Nanoduct conductivity results. In addition, we investigated the relationship between the presence of metabolic alkalosis, hypoelectrolytemia and the clinical diagnosis.

\section{Material and Method}

We retrospectively reviewed the medical records of all children who had sweat conductivity tests from July 2006 to 
November 2010. A total of 2,664 patients were referred for sweat analysis. Few patients had repeated sweat tests with subsequent visits, and the intervals between the tests were less than one month. The study population included patients attending pediatric and pediatric surgery outpatient clinics, and it also included those admitted to the neonatal intensive care unit, pediatric surgery and pediatric medicine wards. There were no patients with known CF. Our hospital was the only training and research state hospital with the facility for sweat conductivity testing at the time of the study, and it was located in the Asian site of Istanbul. Sweat testing was available 5 days per week.

The patients' clinical history and laboratory data were reviewed from the hospital database computer system. A physical examination was conducted for all patients and further investigations were conducted as needed on a clinical basis. For each patient, age, gender, diagnosis and hospitalization number (if hospitalized) were known. Information regarding serum $\mathrm{pH}, \mathrm{pCO}_{2}, \mathrm{HCO}_{3}, \mathrm{Na}, \mathrm{Cl}$ and $\mathrm{K}$ values were recorded when available. In many cases, a family history of atopy, allergy, CF, asthma, tuberculosis, presence of consanguineous marriage and the duration of symptoms were also recorded.

Metabolic alkalosis was defined as blood $\mathrm{pH}$ levels greater than7.45 and/or serum bicarbonate levels higher than $28 \mathrm{mmol} / \mathrm{L}$ in the absence of respiratory insufficiency $\left(\mathrm{PaCO}_{2} \geq 45 \mathrm{mmHg}\right)$. Hypoelectrolytemia was considered if serum sodium, potassium and chloride were under 135, 3.5, and $90 \mathrm{mEq} / \mathrm{L}$ levels, respectively.

The Nanoduct ${ }^{\circledR}$ Neonatal Sweat Analysis System (Wescor Inc., Logan, Utah, Biomedical Products Division) was used for CF sweat test screening. The device was suitable for children under 16 years old, including neonates. Sweat was induced by pilocarpine iontophoresis, and the results were interpreted by continuous-flow analysis on the analyzer display. The flexor aspect of the forearm, approximately halfway between the wrist and elbow, was used for the anodic (positive) skin site. The area was cleaned with alcohol. The results were considered normal if values were between $3-60$ $\mathrm{mmol} / \mathrm{L}$ (equivalent $\mathrm{NaCl}$ ) and intermediate if values were between $61-80 \mathrm{mmol} / \mathrm{L}$. CF was very likely if the results were equal to or above $80 \mathrm{mmol} / \mathrm{L}$ based on the user's manual. The minimum reading value was $3 \mathrm{mmol} / \mathrm{L}$. Tests were conducted at room temperature $\left(22-25^{\circ} \mathrm{C}\right)$ with a relative humidity of approximately $60 \%$

The same laboratory technician who was specifically educated on the use of this device performed the sweat analysis tests on all of the children. Test results were excluded from the study if not enough sweat was produced for analysis. Other than mild skin erythema, no adverse effects from pilocarpine iontophoresis were reported.

The conductivity test was repeated in patients who had values higher than $60 \mathrm{mmol} / \mathrm{L}$ and those with highly suspicious clinical symptoms with normal conductivity results. Values over $60 \mathrm{mmol} / \mathrm{L}$ in the second test were referred

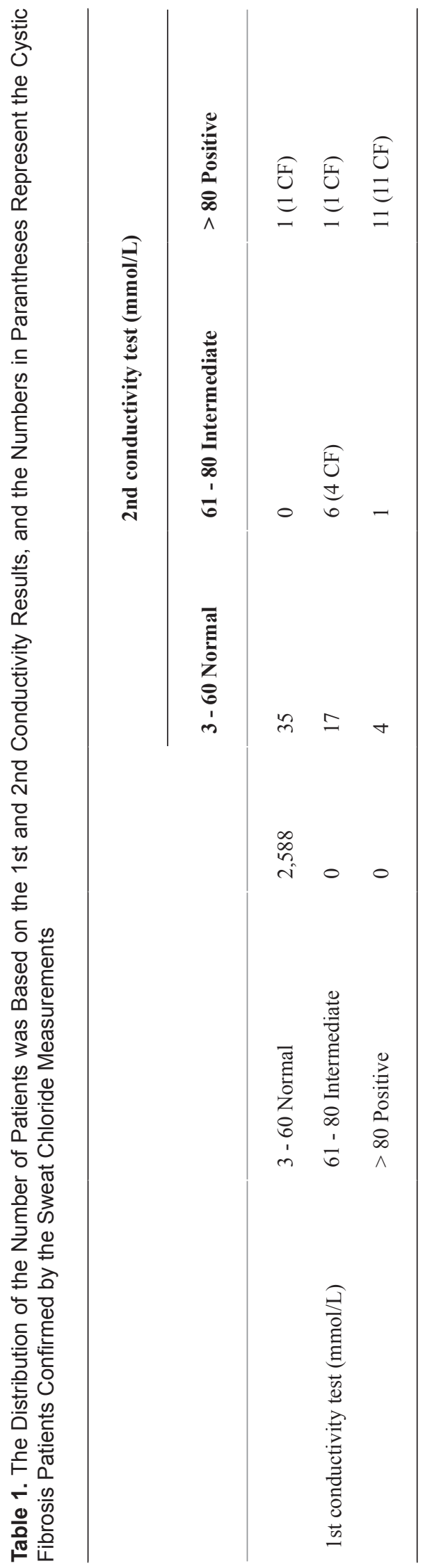



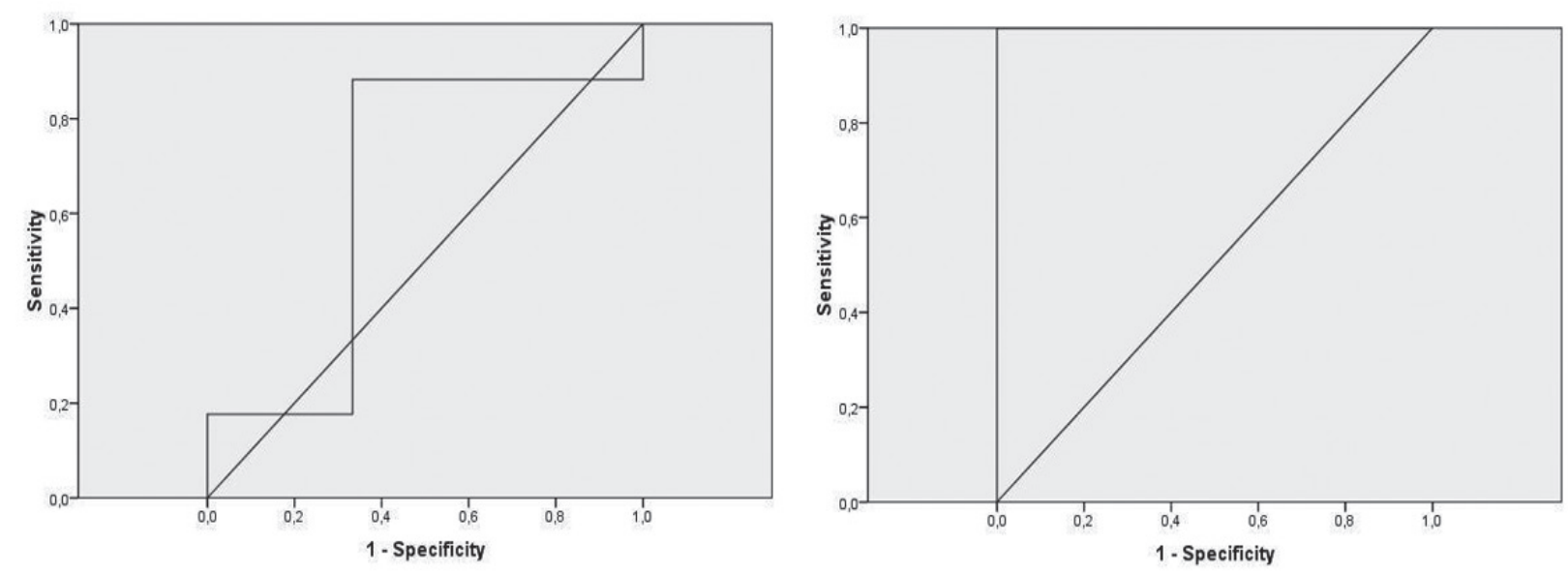

Figure 1. A: the ROC curve for the 1st conductivity test; B: the ROC curve for the 2 nd conductivity test.

for sweat chloride measurements because $\mathrm{CF}$ should not be diagnosed based on conductivity measurements alone [1]. Twenty patients with high conductivity values $(>60$ $\mathrm{mmol} / \mathrm{L}$ ) in the second test and clinical manifestations of CF were referred to the pediatric chest clinic for follow-up. The diagnosis was confirmed in 17 patients with sweat tests, and mutations of the $\mathrm{CF}$ transmembrane conductance regulator gene were found in all of them [10]. Three patients did not have CF. Patients with normal and/or borderline values in the second conductivity test were followed to sufficiently eliminate the diagnosis of $\mathrm{CF}$ on a clinical basis.

\section{Clinical material}

The following 7 groups were studied: 1). Upper respiratory track diseases: including sinusitis, polyp and non-specific cough; 2). Lower respiratory tract diseases: subacute, recurrent or chronic chest diseases including asthma, bronchiolitis, bronchitis, pneumonia, bronchiectasis, and dyspnea; 3 ). Gastrointestinal tract diseases: gastroenteritis, malabsorption diseases such as celiac disease, steatorrhoea, pancreatic insufficiency, and liver disease; 4). Delay of passing stool: volvulus, meconium ileus, ileal atresia, Hirschsprung disease, rectal prolapse, constipation, and abdominal distention; 5). Failure to thrive and protein-energy malnutrition; 6). Allergy classified as allergic rhinitis and any documented allergy; 7). Suspicion of CF: atypical symptoms suggestive of CF or children referred from other institutions for sweat analysis.

The study was approved by the ethical committee of Zeynep Kamil Maternity and Children's Diseases Training and Research State Hospital.

\section{Statistical analysis}

The parametric data were analyzed using paired t-tests. Age groups and conductivity result groups were analyzed by analysis of variance (ANOVA) (SPSS; release 17). The results are presented as the mean \pm standard deviation (SD) and the median (minimum-maximum). The association between the two consecutive conductivity tests was assessed by Pearson correlation coefficients, and non-parametric correlations were assessed using Spearman's correlation coefficients.

The capability of the conductivity test to discriminate between $\mathrm{CF}$ and non-CF subjects was assessed by constructing a receiver operating characteristic (ROC) curve, and the best cut-off values were assessed through the calculations of sensitivity and specificity. A P-value of less than 0.05 was regarded as statistically significant.

\section{Results}

\section{Patient characteristics}

Two thousand six hundred and sixty-four patients with an indication for the sweat test were reviewed in this study. The median age was 17 months with a range of 7 days to 17 years old. There were 1,600 (60.1\%) boys, 896 girls and 68 newborns included in the study.

There were 1,768 (66.4\%) patients from the outpatient clinics, and the remaining 896 patients were hospitalized.

The median age of the patients diagnosed with $\mathrm{CF}$ was 4 months (mean $\pm \mathrm{SD}$ : $13.8 \pm 23.7$; minimum: 1-month; maximum: 84-months). Twelve out of $17 \mathrm{CF}$ patients were hospitalized at the time of diagnosis, and 5 of them were from outpatient clinics. Eight of the patients had a history of multiple hospitalizations before being diagnosed with CF. The median duration of the patients' symptoms was 8.5 days, with a maximum value of 90 days. 


\section{Indications for sweat test}

The most common indication for performing a sweat test was lower respiratory tract manifestation in 1909 patients $(71.7 \%)$. Children with recurrent bouts of pneumonia and bronchiolitis comprised the first indication for the sweat test.

The other indications, in descending order of frequency, included non-specific symptoms suggestive of CF (185 patients), upper respiratory tract diseases (184 patients), failure to thrive (155 patients), gastrointestinal disorders (85 patients), delay of passing stool (78 patients) and allergy (68 patients).

The most common presenting manifestation among $\mathrm{CF}$ patients was lower respiratory tract disorders, as evidenced in 11 patients $(64.7 \%)$. Two patients presented with meconium ileus (11.8\%), and two patients presented with upper respiratory tract manifestations. Gastrointestinal symptoms (1 patient, jaundice) and a failure to thrive (1 patient) were the other presenting manifestations in patients diagnosed with $\mathrm{CF}$.

\section{Sweat conductivity test results}

From the 2,664 patients included in the study, 16 children had sweat conductivity values higher than 80 . There were 76 children who had a second conductivity test, and 13 of them had sweat conductivity values above 80 for the second test (Table 1). The median conductivity values of patients diagnosed with $\mathrm{CF}$ in the consecutive two tests were 91 (mean \pm SD: $88.2 \pm 18.7$; minimum: 54; maximum: $119 \mathrm{mmol} / \mathrm{L}$ ) and 85 (mean \pm SD: $84 \pm 11.2$; minimum: 65; maximum: 99 $\mathrm{mmol} / \mathrm{L})$, respectively.

There were no significant differences between the results from boys and girls $(\mathrm{P}>0.05)$. Age, $\mathrm{pH}, \mathrm{HCO}_{3}, \mathrm{Na}$, $\mathrm{Cl}, \mathrm{K}$ and sweat conductivity test results were statistically related $(\mathrm{P}<0.001)$. Measurements were significantly higher in children older than 2 years (Table 2 ).

The Pearson's correlation between the first and second conductivity test was significant $(\mathrm{r}=0.76, \mathrm{P}<0.001)$. When we correlated sweat chloride results with the first conductivity test, it was not $\operatorname{significant}(\mathrm{r}=0.18, \mathrm{P}>0.05)$. However, the second conductivity test correlation was statistically significant $(\mathrm{r}=0.62, \mathrm{P}=0.003)$. The $\mathrm{ROC}$ curve showed a very high level of agreement between the second conductivity test and the sweat test (Fig. 1) (Table 3).

\section{Arterial blood gas and electrolytes}

Mean $\pm \mathrm{SD}$, median, minimum and maximum values of laboratory parameters among patients with available data are shown based on sweat conductivity results (Table 4). $\mathrm{pH}$, $\mathrm{HCO}_{3}, \mathrm{Na}, \mathrm{Cl}$ and $\mathrm{K}$ were statistically significant based on sweat conductivity results $(\mathrm{P}<0.05)$. The significant differences between the $\mathrm{pH}, \mathrm{HCO}_{3}$ and $\mathrm{Na}$ levels and the conduc-

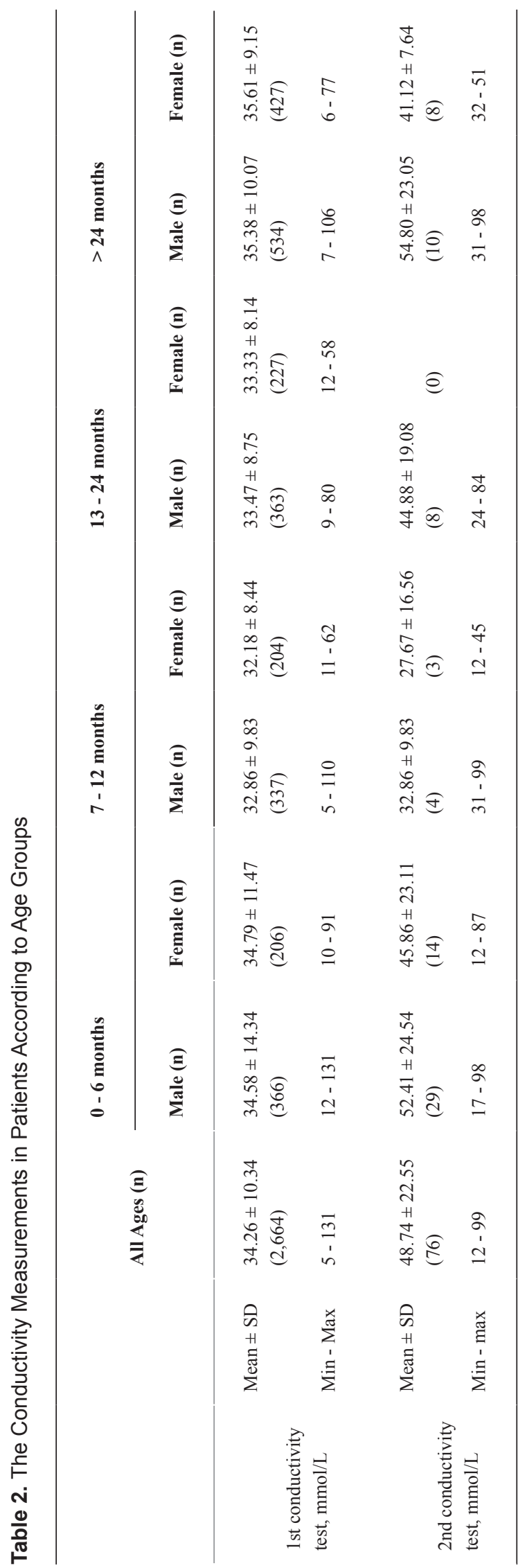


Table 3. Different Conductivity Cut-off Values of the 1st and 2nd Tests to Predict the Cystic Fibrosis Diagnosis, According to the Number of Patients Confirmed by Sweat Chloride Measurements

\begin{tabular}{lllll}
\hline & & $\begin{array}{l}\text { Sensitivity } \\
(\%)\end{array}$ & $\begin{array}{l}\text { Specificity } \\
(\%)\end{array}$ & Area Under Cure \\
\hline 1st conductivity test & $53 \mathrm{mmol} / \mathrm{L}$ & 100 & 100 & 0.647 \\
& $58 \mathrm{mmol} / \mathrm{L}$ & 94 & 100 & $\mathrm{P}>0.05$ \\
2nd conductivity test & $63 \mathrm{mmol} / \mathrm{L}$ & 88 & 100 & 1 \\
& $60 \mathrm{mmol} / \mathrm{L}$ & 100 & 100 & $\mathrm{P}<0.007$ \\
\hline
\end{tabular}

tivity results of the three groups were based on the higher conductivity level ( $>80 \mathrm{mmol} / \mathrm{L}$ ) group. When we compared the $\mathrm{Cl}$ values of the patients based on conductivity results, all three groups of conductivity results were significantly different than each other. Data from the patients diagnosed as $\mathrm{CF}$ are also given in Table 4.

\section{Consanguinity and family history}

Data was available for 816 families. Among 45 families, parents were consanguineous (5.5\%). Consanguineous marriages were between the first or second cousins from the descendants of the same generation. There was 1 family with a family history of CF, and 717 families did not have any known history of disease. A history of asthma was reported in 76 families, and atopy or documented allergy was reported in 9 families. Chronic lung diseases, including tuberculosis, were reported in 13 families.

Two out of $17 \mathrm{CF}$ patients had consanguineous parents, and one patient had a family history of chronic lung disease. There was no significant relationship between consanguinity and the diagnosis of CF $(\mathrm{P}>0.05)$.

\section{Discussion}

The aim of this retrospective cohort study was to report our Nanoduct conductivity results and to detail the indications for ascertaining the sweat conductivity test and laboratory values based on results from patients in Turkey. Among the patients who were referred to our pediatric department with various indications for sweat conductivity analysis over a 4-year period, we were able to identify 40 patients with the sweat conductivity results above threshold ( $>60 \mathrm{mmol} / \mathrm{L})$. The sweat conductivity test has been approved by the $\mathrm{CF}$ Foundation as a screening test at community hospitals [2].
Sweat conductivity may have a role in excluding a diagnosis of CF [2], but sufficient data are not available to recommend the Nanoduct device in diagnosing CF [9]. The consensus committee recommends the following sweat chloride reference ranges for infants up to 6 months: no diagnosis of $\mathrm{CF}$ if values are $\leq 29 \mathrm{mmol} / \mathrm{L}$; intermediate if values are in the range of $30-59 \mathrm{mmol} / \mathrm{L}$; values are indicative of $\mathrm{CF}$ if they are $\geq 60 \mathrm{mmol} / \mathrm{L}$. For infants older than six months the ranges are: $\leq 39,40-59$, and $\geq 60 \mathrm{mmol} / \mathrm{L}$, respectively [9].

Conductivity was shown to have approximately the same capacity for distinguishing between $\mathrm{CF}$ and non-CF patients. In addition, the sensitivity and specificity of conductivity was similar to results obtained from the Gibson and Cook method in the same subjects [6].

A comparison of the Macroduct and Nanoduct systems were studied in two investigations. In 2005, 111 subjects were tested, and the Nanoduct system was found to be reliable in differentiating CF (mean conductivity, $115 \mathrm{mmol} / \mathrm{L}$; range, 92 to 137) from non-CF patients (mean conductivity, $36 \mathrm{mmol} / \mathrm{L}$; range, 17 to 59) [14]. A second study in 2006 performed 110 tests in 100 patients and concluded that the Nanoduct system cannot be used for the diagnosis of CF due to a high false negative rate [7]. In 2008, Desax et al [5] reported the results of Nanoduct sweat analysis in 1,041 patients; the median conductivity level in non-CF subjects was $37.0 \mathrm{mmol} / \mathrm{L}$ (range: $2-108 \mathrm{mmol} / \mathrm{L}$ ), and it was 114.5 $\mathrm{mmol} / \mathrm{L}$ (range: $60-139 \mathrm{mmol} / \mathrm{L}$ ) for CF patients [5]. Assuming that $59 \mathrm{mmol} / \mathrm{L}$ is the upper limit of normal conductivity, the 46 CF patients were correctly diagnosed with a sensitivity of $100 \%$ and a specificity of $95.7 \%$ [5]. In our study, the median conductivity level in non-CF subjects was $33.0 \mathrm{mmol} / \mathrm{L}$, and the median conductivity level in $\mathrm{CF}$ patients was $91 \mathrm{mmol} / \mathrm{L}$ (mean $\pm \mathrm{SD}: 88.2 \pm 18.7$; range: 54 - $119 \mathrm{mmol} / \mathrm{L}$ ).

Sands et al [15] reported results from 487 Nanoduct conductivity tests, and they demonstrated that $\mathrm{CF}$ infants 
Table 4. The Distribution of Laboratory Values Based on Conductivity Results and the Results of the Patients Diagnosed With Cystic Fibrosis. A Comparison of laboratory Values Based on Normal, Intermediate and Positive Conductivity are Also Given (ANOVA)

\begin{tabular}{|c|c|c|c|c|c|c|c|}
\hline & & \multirow{2}{*}{$\begin{array}{l}3-60 \mathrm{mmol} / \mathrm{L} \\
\text { Normal } \\
(\mathrm{n}: 509)\end{array}$} & \multirow{2}{*}{$\begin{array}{l}61-80 \mathrm{mmol} / \mathrm{L} \\
\text { Intermediate } \\
(\mathrm{n:} 9)\end{array}$} & \multirow{2}{*}{$\begin{array}{l}>80 \mathrm{mmol} / \mathrm{L} \\
\text { Positive } \\
(\mathrm{n}: 7)\end{array}$} & \multirow{2}{*}{$\begin{array}{l}\text { CF Patients } \\
(\mathbf{n}: 17)\end{array}$} & \multicolumn{2}{|c|}{ ANOVA } \\
\hline & & & & & & $\mathbf{F}$ & $\mathbf{P}$ \\
\hline \multirow[t]{3}{*}{$\mathrm{Na}$} & Mean \pm SD & $138.42 \pm 3.75$ & $137.72 \pm 3.80$ & $130.21 \pm 5.64$ & $133.43 \pm 6.2$ & 17.1 & $<0.001$ \\
\hline & Median & 139 & 137.5 & 131 & 134 & & \\
\hline & Min - Max & $123-163$ & $131-142$ & $120-137$ & $118-142$ & & \\
\hline \multirow[t]{3}{*}{ K } & Mean \pm SD & $4.53 \pm 0.71$ & $4.45 \pm 0.38$ & $3.67 \pm 0.56$ & $4 \pm 0.6$ & 4.57 & 0.01 \\
\hline & Median & 4.5 & 4.5 & 3.5 & 4.15 & & \\
\hline & Min - Max & $2.3-7.3$ & $3.9-5.2$ & $3.1-4.5$ & $3.1-4.7$ & & \\
\hline \multirow[t]{3}{*}{$\mathrm{Cl}$} & Mean \pm SD & $103.29 \pm 4.30$ & $102.96 \pm 4.52$ & $88.43 \pm 17.23$ & $93.9 \pm 15.5$ & 35.85 & $<0.001$ \\
\hline & Median & 104 & 103 & 88 & 101 & & \\
\hline & Min - Max & $80-138$ & $94-109$ & $64-106$ & $64-108$ & & \\
\hline \multirow[t]{3}{*}{$\mathrm{pH}$} & Mean \pm SD & $7.39 \pm 0.7$ & $7.39 \pm 0.06$ & $7.5 \pm 0.12$ & $7.47 \pm 0.11$ & 8.33 & $<0.001$ \\
\hline & Median & 7.39 & 7.39 & 7.51 & 7.45 & & \\
\hline & Min - Max & $7.0-7.6$ & $7.3-7.5$ & $7.3-7.7$ & $7.3-7.7$ & & \\
\hline \multirow[t]{3}{*}{$\mathrm{pCO}_{2}$} & Mean \pm SD & $37.35 \pm 8.31$ & $36.31 \pm 7.77$ & $38.21 \pm 8.68$ & $37.96 \pm 6.9$ & 0.10 & 0.89 \\
\hline & Median & 36 & 38.5 & 40.4 & 40 & & \\
\hline & Min - Max & $20.6-102.1$ & $23.9-46.2$ & $21-48$ & $23.9-48$ & & \\
\hline \multirow[t]{3}{*}{$\mathrm{HCO}_{3}$} & Mean \pm SD & $22.17 \pm 4.32$ & $22 \pm 3.86$ & $30.64 \pm 14.58$ & $28.37 \pm 12.8$ & 11.98 & $<0.001$ \\
\hline & Median & 21.6 & 22.3 & 25.5 & 25.5 & & \\
\hline & Min - Max & $9.6-43.4$ & $15.6-27.6$ & $17.6-54$ & $15.6-54$ & & \\
\hline
\end{tabular}

had a mean conductivity of $99.8 \pm 18.8 \mathrm{mmol} / \mathrm{L}$, and nonCF infants had mean values of $29.8 \pm 7.7 \mathrm{mmol} / \mathrm{L}$. A high correlation between Nanoduct conductivity results and the classic pilocarpine method was found $(95 \%$ confidence level; $r=0.87$ ) [15]. The optimal cut-off for conductivity tests was $50 \mathrm{mmol} / \mathrm{L}$ with a sensitivity of $100 \%$ and a specificity of $97.5 \%$ [15]. Our results indicated $100 \%$ sensitivity and specificity with a cut-off value of 53 in the first conductivity test and 60 with the consecutive test. Although in our study the number of patients confirmed with sweat $\mathrm{Cl}$ analysis $(\mathrm{n}=$
20) was relatively smaller than in previous studies, the proposed cut-off values of 50 [15] and 59 [5] were similar to our results (53 and 60) in two consecutive tests with the sensitivity of $100 \%$.

Hammond et al [4] found that CF patients had conductivity values of more than $90 \mathrm{mmol} / \mathrm{L}$, and 430 (91\%) nonCF patients had conductivity values of less than $50 \mathrm{mmol} / \mathrm{L}$. They concluded that conductivity was equally satisfactory as chloride measurements [4].

Mishra et al [16] created age-related reference intervals 
for sweat testing using the Wescor Macroduct System. Sweat chloride increased with age in 282 healthy subjects. The estimated median $(95 \% \mathrm{RI})$ values for sweat chloride were: 5 to 9 years, $13 \mathrm{mmol} / \mathrm{L}(1-39 \mathrm{mmol} / \mathrm{L}) ; 10$ to 14 years, 18 $\mathrm{mmol} / \mathrm{L}(3-47 \mathrm{mmol} / \mathrm{L}) ; 15$ to 19 years, $20 \mathrm{mmol} / \mathrm{L}(3-51$ $\mathrm{mmol} / \mathrm{L}$ ); and $20+$ years $23 \mathrm{mmol} / \mathrm{L}(5-56 \mathrm{mmol} / \mathrm{L})$ [16]. Similarly, we also found positive correlations with age and Nanoduct conductivity results $(\mathrm{P}<0.01)$.

Mastella et al [6] reported specificity and sensitivity of 0.962 at the value of $74 \mathrm{mmol} / \mathrm{L}$ for the Macroduct system. Out of 3834 subjects tested with the Macroduct system, the optimal conductivity cut-off value to predict a positive $\mathrm{CF}$ diagnosis was $\geq 90 \mathrm{mmol} / \mathrm{L}$, with $99.66 \%$ sensitivity and $100 \%$ specificity [17]. The optimal value to predict a negative $\mathrm{CF}$ diagnosis was $<75 \mathrm{mmol} / \mathrm{L}$, with $99.25 \%$ sensitivity and $93.37 \%$ specificity [17].

Sweat testing performed at 40 and 60 days of age in 1003 infants revealed no correlation between age and sweat chloride concentration [18]. Heeley et al [3] compared the conductivity results of $\mathrm{CF}$ patients with the non-CF control group. Their control group consisted of 154 children with symptoms of a failure to thrive, gastrointestinal obstruction, diarrhea, respiratory problems, and jaundice. The range of conductivity was $18-71 \mathrm{mmol}(\mathrm{NaCl}$ eq $) / \mathrm{L}$ in the control group, whereas it was $67-141 \mathrm{mmol}(\mathrm{NaCl}$ eq)/L in the CF group. Older children (9 - 15 years) in the control group showed increased sweat test results that overlapped with those of CF patients [3].

The mean age at diagnosis of CF was 52.7 months in India [19] and 2.88 \pm 3.5 years in Saudi Arabia [20], whereas the mean age at onset of symptoms was $10.7 \pm 19.5$ months [19]. The mean age at the time of diagnosis in Turkey was $31.2 \pm 41.4$ (range: 1.5 - 168) months [12]. In our study, the mean age at diagnosis was $13.8 \pm 23.7$ months with a median of 4 months. The duration of time between the onset of symptoms and the diagnosis of CF illustrates the need for an educational program for medical staff about CF.

Bar-Zohar et al [21] retrospectively studied 255 children who were referred for sweat testing from 1991 - 1996 [21]. The prevalence of asthma was $36.5 \%$, and the prevalence of the failure to thrive was $7.9 \%$ [21]. The prevalence of asthma and the failure to thrive in our cohort was $5.6 \%$ and $4 \%$, respectively.

Hyponatremia, hypochloremia and metabolic alkalosis are well recognized in CF patients. These can occur both as a presentation or a complication of CF [22]. Pseudo- Bartter Syndrome in children with CF should be identified early to avoid recurrent attacks and high morbidity. The prevalence of pseudo-Bartter Syndrome was reported to be between $12 \%$ [23] and $17.6 \%$ [24] in Turkey. The mean \pm SD values of electrolytes and arterial blood gas in CF patients were as follows: plasma sodium, $126.1 \pm 6.0$; potassium, $3.1 \pm 0.7$; chloride, $77.8 \pm 19.4$; blood $\mathrm{pH}, 7.6 \pm 0.6$; and bicarbonate, $38.9 \pm 5.5 \mathrm{mmol} / \mathrm{L}[24]$. Yalcin et al [23] found similar mean values of plasma sodium, potassium and chloride: 126, 3.1 and $79 \mathrm{mmol} / \mathrm{L}$, respectively. The mean blood $\mathrm{pH}$ was 7.53 , and the mean bicarbonate was $35 \mathrm{mmol} / \mathrm{L}$ [23]. In our study, the mean \pm SD values of electrolytes and arterial blood gas in CF patients were as follows: plasma sodium, $133.43 \pm 6.2$; potassium, $4 \pm 0.6$; chloride, $93.9 \pm 15.5$; blood $\mathrm{pH}, 7.47 \pm$ 0.11 ; and bicarbonate $28.37 \pm 12.8 \mathrm{mmol} / \mathrm{L}$.

The incidence of metabolic alkalosis with hypoelectrolytemia was $16.5 \%$ in an infant CF population in Macedonia [25] and 16.2\% in Spain [22]. Metabolic alkalosis with low electrolytes as the presentation of $\mathrm{CF}$ was $16.8 \%$ in $77 \mathrm{CF}$ patients between the ages of 3 and 14 months [26]. Ozcelik et al [27] reported a sodium chloride deficiency in 12 of 46 CF patients who had mean plasma sodium, potassium and chloride levels of 122.9 (range 106 - 135), 2.5 (range 1.6 - 3.5), and 73.3 (range 60 - 90) $\mathrm{mEq} / \mathrm{L}$, respectively [27]. Unexplained hypochloremic metabolic alkalosis should always be considered in the diagnosis of CF. We believe that metabolic alkalosis with hypoelectrolytemia is suggestive of $\mathrm{CF}$ and should be referred for sweat testing.

Consanguinity was not found to be major factor contributing to the incidence of CF in Turkey [10]. The highest genetic heterogeneity in a population with respect to CF was found, and a minimum carrier frequency of 1 in 50 was assessed in the Turkish population with under-diagnosed CF [10]. In our study, there were 45 consanguineous marriages, but we did not find any significant relationship between consanguinity and the diagnosis of CF in our patients.

Unfortunately, our study had several limitations. Data for arterial blood gas and electrolytes were not available in all cases because of the retrospective design. Some of our patients might have been treated later at another hospital for recurrent symptoms, so we may not know the true percentage of patients with CF. Most of the data in the literature comes from highly qualified CF centers, and there is not enough data from non-specialized clinical settings. The purpose of this study was to report the ways in which we attempt to deal with the high numbers of patients with suspected CF, without enough pediatric pulmonologists and qualified CF centers. Data reported in the present work provide support for the need of neonatal screening programs in developing countries with a high incidence of CF carriers.

\section{Acknowledgement}

The authors are indebted to Sumeyye Yildiz for technical assistance in sweat conductivity testing.

\section{Conflict of Interest Statement}

The authors report no potential conflicts of interest and financial disclosure. 


\section{References}

1. Green A, Kirk J. Guidelines for the performance of the sweat test for the diagnosis of cystic fibrosis. Ann Clin Biochem. 2007:44(Pt 1):25-34.

2. LeGrys VA, Yankaskas JR, Quittell LM, Marshall BC, Mogayzel PJ, Jr. Diagnostic sweat testing: the Cystic Fibrosis Foundation guidelines. J Pediatr. 2007;151(1):8589.

3. Heeley ME, Woolf DA, Heeley AF. Indirect measurements of sweat electrolyte concentration in the laboratory diagnosis of cystic fibrosis. Arch Dis Child. 2000;82(5):420-424.

4. Hammond KB, Turcios NL, Gibson LE. Clinical evaluation of the macroduct sweat collection system and conductivity analyzer in the diagnosis of cystic fibrosis. J Pediatr. 1994;124(2):255-260.

5. Desax MC, Ammann RA, Hammer J, Schoeni MH, Barben J. Nanoduct sweat testing for rapid diagnosis in newborns, infants and children with cystic fibrosis. Eur J Pediatr. 2008;167(3):299-304.

6. Mastella G, Di Cesare G, Borruso A, Menin L, Zanolla L. Reliability of sweat-testing by the Macroduct collection method combined with conductivity analysis in comparison with the classic Gibson and Cooke technique. Acta Paediatr. 2000;89(8):933-937.

7. Losty HC, Wheatley H, Doull I. The evaluation of a novel conductometric device for the diagnosis of cystic fibrosis. Ann Clin Biochem. 2006;43(Pt 5):375-381.

8. Mastella G. Sweat testing: can the conductivity analysis take the place of the classic Gibson and Cooke technique? J Pediatr (Rio J). 2010;86(2):89-91.

9. Farrell PM, Rosenstein BJ, White TB, Accurso FJ, Castellani C, Cutting GR, Durie PR, et al. Guidelines for diagnosis of cystic fibrosis in newborns through older adults: Cystic Fibrosis Foundation consensus report. J Pediatr. 2008;153(2):S4-S14.

10. Kilinc MO, Ninis VN, Dagli E, Demirkol M, Ozkinay F, Arikan Z, Cogulu O, et al. Highest heterogeneity for cystic fibrosis: 36 mutations account for $75 \%$ of all CF chromosomes in Turkish patients. Am J Med Genet. 2002;113(3):250-257.

11. Bobadilla JL, Macek M, Jr., Fine JP, Farrell PM. Cystic fibrosis: a worldwide analysis of CFTR mutations--correlation with incidence data and application to screening. Hum Mutat. 2002;19(6):575-606.

12. Uzuner N, Urgenalp A, Babayigit A et al. Characteristics of the patients with cystic fibrosis. J Cyst Fibros 2007; 6:39.

13. Cystic Fibrosis Foundation Patient Registry. Annual Data Report to the Center Directors. Bethesda, MD: Cystic Fibrosis Foundation; 2007.

14. Barben J, Ammann RA, Metlagel A, Schoeni MH. Con- ductivity determined by a new sweat analyzer compared with chloride concentrations for the diagnosis of cystic fibrosis. J Pediatr. 2005;146(2):183-188.

15. Sands D, Oltarzewski M, Nowakowska A, Zybert K. Bilateral sweat tests with two different methods as a part of cystic fibrosis newborn screening (CF NBS) protocol and additional quality control. Folia Histochem Cytobiol. 2010;48(3):358-365.

16. Mishra A, Greaves R, Smith K, Carlin JB, Wootton A, Stirling R, Massie J. Diagnosis of cystic fibrosis by sweat testing: age-specific reference intervals. J Pediatr. 2008;153(6):758-763.

17. Lezana JL, Vargas MH, Karam-Bechara J, Aldana RS, Furuya ME. Sweat conductivity and chloride titration for cystic fibrosis diagnosis in 3834 subjects. J Cyst Fibros. 2003;2(1):1-7.

18. Taccetti G, Festini F, Braccini G, Campana S, de Martino M. Sweat testing in newborns positive to neonatal screening for cystic fibrosis. Arch Dis Child Fetal Neonatal Ed. 2004;89(5):F463-464.

19. Shastri SS, Kabra M, Kabra SK, Pandey RM, Menon PS. Characterisation of mutations and genotype-phenotype correlation in cystic fibrosis: experience from India. J Cyst Fibros. 2008;7(2):110-115.

20. Banjar HH. Cystic fibrosis: presentation with other diseases, the experience in Saudi Arabia. J Cyst Fibros. 2003;2(3):155-159.

21. Bar-Zohar D, Segal-Algranati D, Belson A, Reif S. Diagnosing cystic fibrosis--asthma and failure to thrive as indications for a sweat test. J Med. 2004;35(1-6):93103.

22. Sojo A, Rodriguez-Soriano J, Vitoria JC, Vazquez C, Ariceta G, Villate A. Chloride deficiency as a presentation or complication of cystic fibrosis. Eur J Pediatr. 1994;153(11):825-828.

23. Yalcin E, Kiper N, Dogru D, Ozcelik U, Aslan AT. Clinical features and treatment approaches in cystic fibrosis with pseudo-Bartter syndrome. Ann Trop Paediatr. 2005;25(2):119-124.

24. Ozturk Y, Soylu OB, Arslan N. Prevalence and clinical features of cystic fibrosis with pseudo-Bartter syndrome. Ann Trop Paediatr. 2006;26(2):155.

25. Fustik S, Pop-Jordanova N, Slaveska N, Koceva S, Efremov G. Metabolic alkalosis with hypoelectrolytemia in infants with cystic fibrosis. Pediatr Int. 2002;44(3):289292.

26. Ballestero Y, Hernandez MI, Rojo P, Manzanares J, Nebreda $\mathrm{V}$, Carbajosa $\mathrm{H}$, Infante $\mathrm{E}$, et al. Hyponatremic dehydration as a presentation of cystic fibrosis. Pediatr Emerg Care. 2006;22(11):725-727.

27. Ozcelik U, Gocmen A, Kiper N, Coskun T, Yilmaz E, Ozguc M. Sodium chloride deficiency in cystic fibrosis patients. Eur J Pediatr. 1994;153(11):829-831. 